\title{
ELL NEWS
}

Formal association between $E L L$ and ISLE

The Editors and Cambridge University Press are delighted to announce that commencing with the present issue English Language and Linguistics is formally associated with the International Society for the Linguistics of English (ISLE; www.isle-linguistics.org) as its official journal. We believe that ELL and ISLE are a perfect match in that both aim to promote research on the English language worldwide. We are confident that this exciting collaboration will be beneficial to the field of English linguistics and all its practitioners. We are working with ISLE on benefits for members; details will be made available on the ISLE website during 2012.

\section{Editors and the Editorial Board}

After almost fifteen years of highly appreciated service, ELL is saying farewell to David Denison. Although he stepped down as Editor in early 2011, he continued the editing of articles he had already taken on, but that work is coming to an end now. David's place as Editor has been taken by Wim van der Wurff, who will mainly look after submissions in the field of historical syntax and morphology.

$E L L$ is also preparing to say farewell to Bas Aarts, in his capacity as Editor. Over the course of this year, he will be handing over responsibility for submissions in present-day English syntax and morphology to Bernd Kortmann. However, ELL will not altogether lose Bas's input, since he will continue as Book Review Editor.

Finally, as part of a periodic change in membership there will also be several changes to our Editorial Board. Details will be given in issue 16.2. The current composition is shown on the inside cover of the journal. 